\title{
Effects of different doses of testosterone on gonadotropins, 25-hydroxyvitamin D3, and blood lipids in healthy men
}

This article was published in the following Dove Press journal:

Substance Abuse and Rehabilitation

10 December 2014

Number of times this article has been viewed

\section{Nina Gårevik \\ Anders Rane \\ Linda Björkhem-Bergman \\ Lena Ekström}

Division of Clinical Pharmacology, Department of Laboratory Medicine, Karolinska Institutet, Karolinska University Hospital, Stockholm, Sweden
Correspondence: Nina Gårevik

Division of Clinical Pharmacology Cl:68,

Karolinska University Hospital, Huddinge,

SE-14I 86 Stockholm, Sweden

Tel +4685858 0l 28

Email nina.garevik@ki.se
Aims: To study the effect and time profile of different doses of testosterone enanthate on the blood lipid profile and gonadotropins.

Experimental design: Twenty-five healthy male volunteers aged 27-43 years were given $500 \mathrm{mg}, 250 \mathrm{mg}$, and $125 \mathrm{mg}$ of testosterone enanthate as single intramuscular doses of Testoviron ${ }^{\circledR}$ Depot. Luteinizing hormone (LH), follicle-stimulating hormone (FSH), blood lipid profile (total cholesterol, plasma [p-] low-density lipoprotein, p-high-density lipoprotein [HDL], p-apolipoprotein A1 [ApoA1], p-apolipoprotein B, p-triglycerides, p-lipoprotein(a), serum [s-] testosterone, and 25-hydroxyvitamin D3) were analyzed prior to, and 4 and 14 days after dosing. Testosterone and epitestosterone in urine (testosterone/epitestosterone ratio) were analyzed prior to each dose after a washout period of 6-8 weeks.

Results and discussion: All doses investigated suppressed the LH and FSH concentrations in serum. LH remained suppressed 6 weeks after the $500 \mathrm{mg}$ dose. These results indicate that testosterone has a more profound endocrine effect on the hypothalamic-pituitary-gonadal axis than was previously thought. There was no alteration in 25-hydroxyvitamin D3 levels after testosterone administration compared to baseline levels. The 250 and $500 \mathrm{mg}$ doses induced decreased concentrations of ApoA1 and HDL, whereas the lowest dose (125 mg) did not have any effect on the lipid profile.

Conclusion: The single doses of testosterone produced a dose-dependent increase in serum testosterone concentrations together with suppression of s-LH and s-FSH. Alterations in ApoA1 and HDL were observed after the two highest single doses. It is possible that long-time abuse of anabolic androgenic steroids will lead to alteration in vitamin D status. Knowledge and understanding of the side effects of anabolic androgenic steroids are important to the treatment and care of abusers of testosterone.

Keywords: anabolic androgenic steroids, testosterone, gonadotropins, vitamin D, blood lipids, abuse

\section{Introduction}

"Anabolic androgenic steroids" (AASs) are chemical modifications of testosterone. ${ }^{1}$ Testosterone is one of the most frequently abused AASs in society, along with nandrolone and stanozolol, ${ }^{2-4}$ and is considered a widespread public-health problem. ${ }^{5}$ The major purpose of AAS abuse is to improve the user's esthetic appearance and strength by the anabolic effects. ${ }^{6}$ The abuse of these substances is associated with psychiatric side effects such as affective symptoms, loss of impulse control, aggression, and suicide. ${ }^{7}$ Somatic adverse reactions of AAS abuse include disturbances in the lipid profile, cardiovascular effects, dermal manifestations, and endocrine adverse reactions. ${ }^{8}$ Decreased secretion of the pituitary luteinizing hormone (LH) and follicle-stimulating 
hormone (FSH) is commonly reported. ${ }^{9}$ These effects result from the negative feedback of androgens on the hypothalamic-pituitary-gonadal axis, and possibly from the local suppressive effects of exogenous androgens on the testes. ${ }^{10}$ Long persistence of low levels of gonadotropins has been described in nandrolone abusers, with a significant correlation between 19-norandrosterone and $\mathrm{LH}$ and $\mathrm{FSH}^{9}{ }^{9}$

Abuse of AASs leads to increased levels of low-density lipoprotein (LDL) and apolipoprotein B (ApoB; the major component of the LDL particle), but also a decreased level of high-density lipoprotein (HDL) and apolipoprotein A1 (ApoA1; the major component of the HDL particle). ${ }^{11,12}$ A perturbation in the lipoprotein profile has been observed even after one single dose of testosterone in healthy volunteers through increased total cholesterol levels and induced expression of 3-hydroxy-3-methyl-glutaryl-CoA reductase, 2 days after administration. ${ }^{13}$ Stanozolol has been studied with respect to its effect on HDL and found to give a $71 \%$ decrease in HDL levels after 7 days' treatment in association with changes in hepatic triglyceride lipase. ${ }^{14}$ These effects on the lipid profile during long-term abuse are associated with an increased risk of coronary artery disease. ${ }^{15}$ In contrast to their unfavorable effects on lipids, AASs may favorably lower lipoprotein(a) (Lp[a]) concentrations. ${ }^{12}$ "Lp(a)" is an LDL-like particle and contains, in addition to LDL, a specific protein component, apolipoprotein(a) (apo[a]). High levels of Lp(a) have been reported as a risk factor for ischemic heart disease and peripheral vascular disease. ${ }^{16}$

The use of supra-physiological doses of AASs may also disturb the hormone balance of other cholesterol-derived substances, such as vitamin D. It has been shown in a previous study that 12 months' testosterone treatment in hypogonadal men increases the level of 25-hydroxyvitamin D, but, as far as we are aware, no studies have investigated AAS doping and its impact on vitamin D status. ${ }^{17}$

In order to detect testosterone doping, the concentration of testosterone and of several other androgen metabolites in the urine are measured. To increase the sensitivity of the test, the athlete biological passport has been implemented ${ }^{18}$ in sport. Moreover, recently developed AAS detection techniques ${ }^{19,20}$ have been described.

In the study presented here, we investigated the effects of different doses of testosterone on 25 healthy male volunteers. The lipoprotein profile and the endocrine profile were analyzed prior to and 4 and 14 days after the administration of single doses of 500, 250, and $125 \mathrm{mg}$ testosterone enanthate in healthy volunteers.

\section{Methods}

Determination of testosterone/epitestosterone $(\mathrm{T} / \mathrm{E})$ ratio was made with a validated gas chromatography-mass spectrometry method ${ }^{21}$ at our World Anti-Doping Agency-accredited doping laboratory within the Division of Clinical Pharmacology, Karolinska Institutet, Karolinska University Hospital, Stockholm, Sweden. All serum (s-) (s-FSH, s-LH, and s-testosterone) and plasma ( $\mathrm{p}-$ ) analyses (p-cholesterol, p-LDL, p-ApoB, p-HDL, p-ApoA1, p-Lp(a), p-triglycerides, and p-25-hydroxyvitamin D3) were made by routine methods at the Division of Clinical Chemistry. The lipoproteins were analyzed using chromatography (liquid chromatography-mass spectrometry/mass spectrometry) methods, whereas the hormones and vitamin D were measured using fluorescence immunochemistry and radioimmunoassay, respectively.

\section{Subjects and design}

The study was conducted according to the Declaration of Helsinki and the International Conference on Harmonisation Guideline for Good Clinical Practice. The study subjects were 25 male volunteers aged 27-43 years (mean \pm standard deviation, 33.8 \pm 4.7$)$. All participants underwent a medical examination that included laboratory tests before enrollment. All participants were negative in screening tests for illegal drugs, AASs, HIV, and hepatitis B or C virus. None was on any other medication. The participants were given 500, 250, and $125 \mathrm{mg}$ testosterone enanthate as an intramuscular dose of Testoviron ${ }^{\circledR}$ Depot with a washout period of 6-8 weeks between doses. Two participants did not take part in the $125 \mathrm{mg}$ dose study. Blood samples were collected prior to testosterone administration (Day 0), and 4 (Day 4) and 14 days (Day 14) after testosterone administration. Blood samples were collected between 7.00 am and 9.00 am after an overnight fast. Urine samples were collected before administration (Day 0).

All participants gave informed consent consistent with the approval of the Karolinska Institutet Ethics Review Board.

\section{Data analysis}

Statistical analyses were performed using MedCalc software (v 12.2.1.0; MedCalc Software bvba, Ostend, Belgium). Data are presented as means ( \pm standard deviations), or for $\mathrm{Lp}(\mathrm{a})$ as mean (range). The serum markers for the lipid profile, gonadotropins, and testosterone were compared with repeated-measures analysis of variance. LH on Day 0 (the day the $500 \mathrm{mg}$ dose and the day $250 \mathrm{mg}$ dose were administered), were compared with paired Student's $t$-test. Because of the skewed distribution, $\mathrm{Lp}$ (a) levels were compared using the Friedman test. 


\section{Results}

Before the administration of each new intramuscular dose of testosterone enanthate - that is, after a 6-8-week washout period - all the urine $\mathrm{T} / \mathrm{E}$ ratios were back to baseline values. Mean ( \pm standard deviation) $\mathrm{T} / \mathrm{E}$ values prior to the 500,250 , and $125 \mathrm{mg}$ doses were $1.18 \pm 0.98,1.32 \pm 1.08$, and $1.14 \pm 0.83$, respectively.

All participants had s-LH (reference range 1.2-9.6 IU/L) and s-FSH (reference range 1.0-10.0 IU/L) concentrations within the normal range prior to first dose (Day 0) of testosterone enanthate $500 \mathrm{mg}$ (mean values $3.46 \pm 0.22 \mathrm{IU} / \mathrm{L}$ and $3.27 \pm 0.32 \mathrm{IU} / \mathrm{L}$, respectively). Prior to the second administration of testosterone enanthate $(250 \mathrm{mg})$ - that is, after a 6-8-week washout period - there was a significant decrease $(P=0.01)$ in s-LH concentrations. Two of the individuals even had s-LH concentrations below the reference range (Figure 1). Prior to the third administration of testosterone enanthate (125 mg), all s-LH concentrations were within the reference range (mean value $3.25 \pm 0.32 \mathrm{IU} / \mathrm{L}$ ).

S-LH and s-FSH were significantly decreased after the first $(500 \mathrm{mg})$, second $(250 \mathrm{mg})$, and third $(125 \mathrm{mg})$ doses on Days 4 and $14(P<0.0001)$. There was a $73 \%$ and $92 \%$ decrease in LH on Days 4 and 14, respectively, after the $500 \mathrm{mg}$ dose, and the corresponding values for $\mathrm{FSH}$ levels were $63 \%$ and $94 \%$, respectively. After the $250 \mathrm{mg}$ dose, LH decreased by $77 \%$ and $78 \%$ on Days 4 and 14 ,

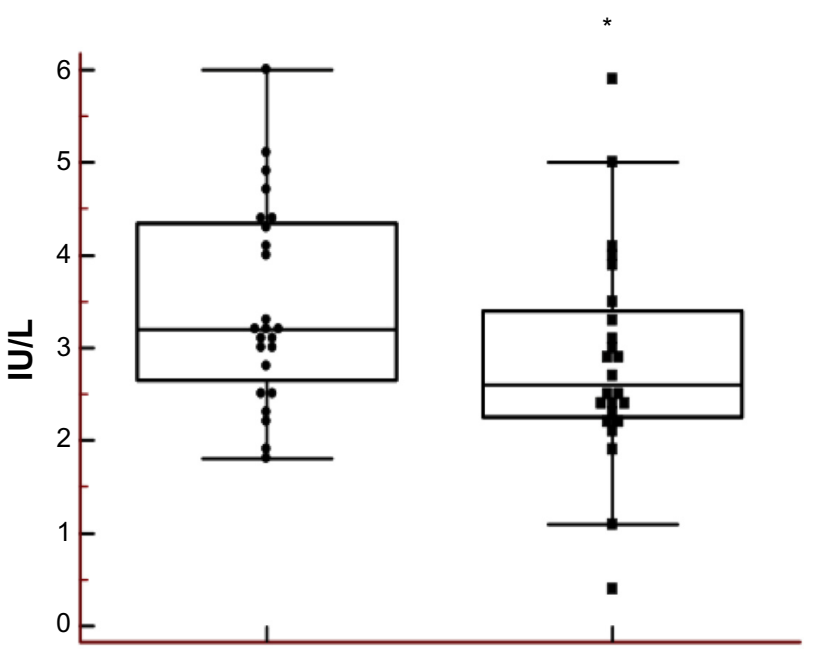

Day 0, dose 1, (500 mg) Day 0, dose 2, (250 mg)

Figure I Sustained effect on luteinizing hormone $(\mathrm{LH})$ after injection of testosterone (500 mg).

Notes: Left box plot prior to dose, right box plot 6-8 weeks after. The asterisk denotes a statistically significant difference between Day 0, Dose I and Day 0, Dose $2(* P=0.01$ [Student's paired $t$-test, results are mean \pm standard deviation]) $(2.85 \pm \mathrm{I} .16 \mathrm{IU} / \mathrm{L})$ compared with Day $0(3.46 \pm 1.08 \mathrm{IU} / \mathrm{L})$ before the first dose. Two individuals even had serum-LH concentrations below the reference range ( 0.4 and I.I IU/L) before the second dose (Day 0), compared with Day 0 before the first dose (3.2 and $2.8 \mathrm{IU} / \mathrm{L}$ ). respectively, and the corresponding values for $\mathrm{FSH}$ were $71 \%$ and $83 \%$, respectively. After the $125 \mathrm{mg}$ dose, $\mathrm{LH}$ decreased by $65 \%$ and $35 \%$ on Days 4 and 14 , respectively, and the corresponding values for FSH were $45 \%$ and $38 \%$, respectively. All individual changes in s-LH and s-FSH concentrations are shown in Figure 2.

All participants had s-testosterone concentrations in the normal range $(10-30 \mathrm{nmol} / \mathrm{L})$ before the first dose of $500 \mathrm{mg}(15.02 \pm 0.76 \mathrm{nmol} / \mathrm{L})$ of testosterone enanthate. The concentration of s-testosterone increased $360 \%$ and $39 \%$ on Days 4 and 14, respectively, after the $500 \mathrm{mg}$ dose $(P<0.0001)$. After the $250 \mathrm{mg}$ and the $125 \mathrm{mg}$ doses, the increase on Day 4 was $112 \%$ and $91.06 \%$, respectively $(P<0.0001)$, but no increase remained on Day 14 after these two doses. Moreover, there was a significant $11 \%$ decrease $(P<0.05)$ on Day 14 after the $125 \mathrm{mg}$ dose (Figure 3).

p-ApoA 1 concentrations decreased $12 \%$ and $18 \%, 4$ and 14 days, respectively, after administration of $500 \mathrm{mg}$ of testosterone enanthate $(P<0.0001)$. After the second dose $(250 \mathrm{mg})$, there was no change in $\mathrm{p}-\mathrm{ApoA} 1$ concentrations on Day 4 but on Day 14 there was a $12 \%$ decrease $(P<0.05)$. There was no significant change of the ApoA1 concentrations after the lowest dose. p-HDL cholesterol concentrations decreased by $8 \%$ and $10 \%$ on Days 4 and 14, respectively, after administration of 500 mg of testosterone enanthate $(P<0.001)$; the corresponding values after $250 \mathrm{mg}$ were $8 \%$ and $15 \%(P<0.001)$, respectively. There was no significant change in p-HDL cholesterol concentrations after the lowest dose. $\mathrm{Lp}$ (a) decreased by 14\%, 14 days after administration of $500 \mathrm{mg}$ of testosterone enanthate $(P<0.05)$. (All significant changes are shown in Table 1$)$.

There was no alteration in 25-hydroxyvitamin D3 levels prior to (mean $58.4 \pm 28.7 \mathrm{nmol} / \mathrm{L}$ ) administration, or at 4 (mean $53.5 \pm 22.9 \mathrm{nmol} / \mathrm{L}$ ) or 14 days (mean $52.6 \pm 16.45$ ) after administration of $500 \mathrm{mg}$ of testosterone enanthate. Since the highest dose did not have any effect on the 25-hydroxyvitamin D3 levels, the other doses were not investigated. At the baseline value, there were no correlations between 25 -hydroxyvitamin D3 and the concentration of total testosterone or the gonadotropins (LH and FSH). Four days post-administration of the $500 \mathrm{mg}$ testosterone enanthate dose, there was a positive correlation between 25-hydroxyvitamin D3 and testosterone ( $r=0.60, P=0.02$ ). This positive correlation did not remain 14 days after administration of the testosterone.

\section{Discussion}

We investigated the effects of testosterone on gonadotropins using different doses of testosterone. Notably, LH remained repressed as long as 6 weeks after the $500 \mathrm{mg}$ single dose, 
A

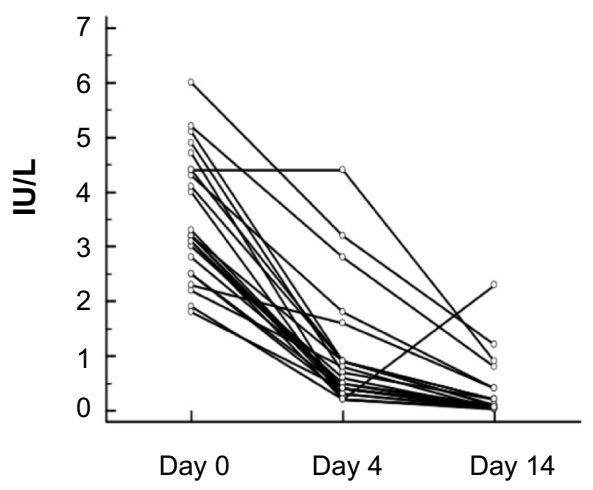

C

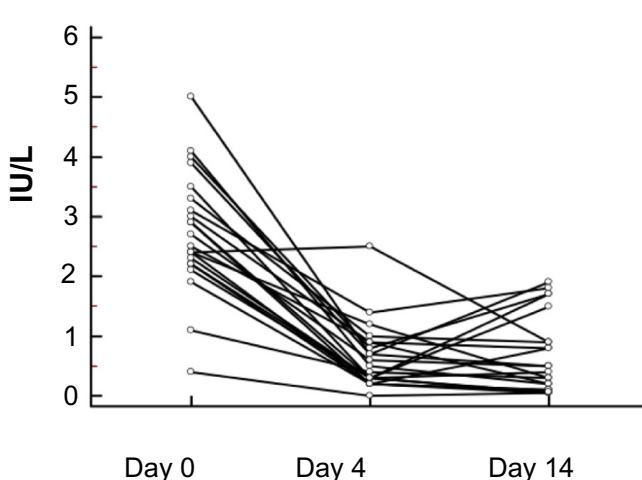

Day 0

Day 4
B

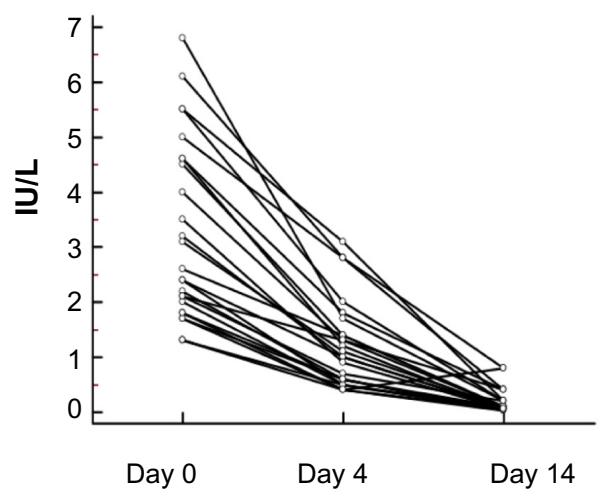

D

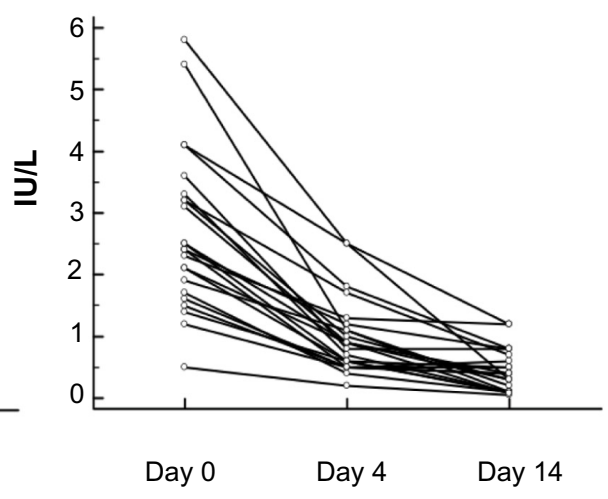

F

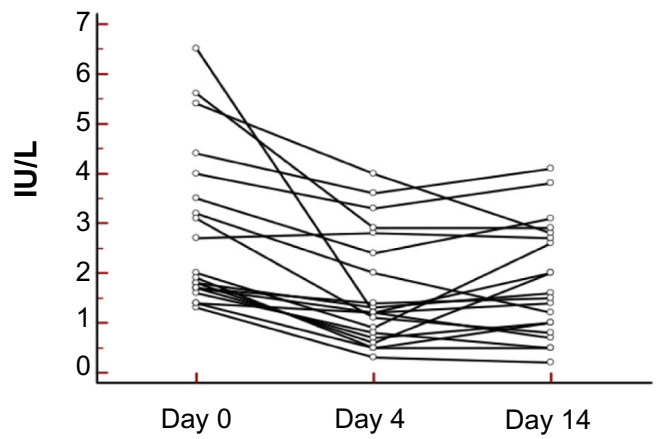

Figure 2 Dose-dependent suppression of serum (s-) luteinizing hormone (LH) and s-follicle-stimulating hormone (FSH) after different parenteral doses of testosterone enanthate.

Notes: (A) s-LH before and after $500 \mathrm{mg}$ testosterone. (B) s-FSH before and after $500 \mathrm{mg}$ testosterone. (C) s-LH before and after $250 \mathrm{mg}$ testosterone. (D) s-FSH before and after $250 \mathrm{mg}$ testosterone. (E) s-LH before and after $125 \mathrm{mg}$ testosterone. (F) s-FSH before and after I $25 \mathrm{mg}$ testosterone. "Day 0" refers to values before administration. Each line represents one individual. LH and FSH were significantly decreased at 4 and 14 days after the administration of testosterone at all three doses investigated.

and for two individuals, LH was still below the lower limit of the reference range. These results indicate that a single dose of testosterone has a more profound and sustained endocrine effect on the hypothalamic-pituitary-gonadal axis than was previously known. It has been shown that after the long-time use of testosterone (26 weeks), LH and FSH levels do not return to normal until 12 weeks following cessation. ${ }^{22}$
This study demonstrates that only the two highest doses (250 and $500 \mathrm{mg}$ ) yielded an increase in s-testosterone concentrations. There was a large variation among individuals in s-testosterone concentrations post-testosterone administration. This may partly be explained by variation in body weight, as was observed in a previous study where healthy men were administered $500 \mathrm{mg}$ testosterone 


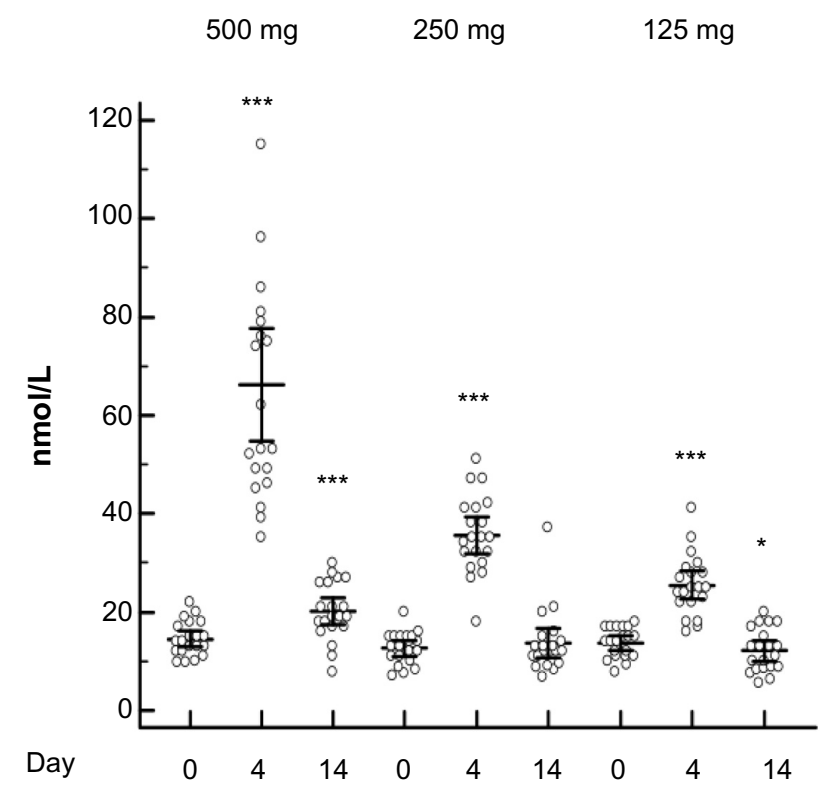

Figure 3 Serum testosterone levels still elevated 14 days after $500 \mathrm{mg}$ testosterone intramuscular dose but not after the $250 \mathrm{mg}$ or $125 \mathrm{mg}$ dose.

Notes: After the administration of 500, 250, and $125 \mathrm{mg}$ testosterone enanthate, there was a significant increase $(P<0.000 \mathrm{I})$ in serum testosterone levels 4 days after administration; this remained at 14 days after administration of the $500 \mathrm{mg}$ dose of testosterone. Fourteen days after administration of $125 \mathrm{mg}$ of testosterone, there was a significant decrease $(P<0.05)$. Analysis of variance repeated-measures adjustment for multiple comparisons, Bonferroni corrected. $* P<0.05 ; * * * P<0.001$.

enanthate. Even more important may be the genetic variation in the phosphodiesterase $P D E 7 B$ gene, which is a determinant of the bioavailability of testosterone enanthate. ${ }^{23}$ The organic anion transporting polypeptide encoded by the SLCO2B1 gene was also found by us to be associated with the serum concentration of testosterone after administration of $500 \mathrm{mg}$ testosterone enanthate. ${ }^{24}$ The decrease in total s-testosterone observed 14 days after the $125 \mathrm{mg}$ dose was probably due to a suppression of the endogenous production of testosterone, whereas, when the higher doses of testosterone were administered, the concentrations on Day 14 were mainly contributed to by exogenous testosterone. It is to be noted that all three doses suppressed the gonadotropins (LH and FSH).

Testosterone is considered a "safe" AAS drug due its "short detection time" (weeks) in contrast to nandrolone, abuse of which may be detectable up to 1 year after discontinuation by repression of the gonadotropins. ${ }^{9}$ In our study, even though an endocrine effect remained several weeks post-testosterone administration, the urinary $\mathrm{T} / \mathrm{E}$ ratios (the biomarker for testosterone doping) were back to baseline before each new dose was given. A large inter-individual variation in T/E ratio was observed on all days studied. The $\mathrm{T} / \mathrm{E}$ ratio is highly dependent on the $U G T 2 B 17$ gene deletion polymorphism, and, consistent with results from a previous study, individuals homozygous for gene deletion in our study had a low T/E $(<0.4) .{ }^{25}$ Our results indicate that LH may be a more time-sensitive marker of testosterone doping than the T/E ratio itself. This result is in agreement with a previous study. ${ }^{26}$

In agreement with other findings on AAS abuse and blood lipids, we found a decrease in ApoA1 and HDL after testosterone administration. ${ }^{11,12,14}$ The maximum difference in the lipid profile occurred 14 days after administration of the $500 \mathrm{mg}$ dose, in ApoA1. HDL followed the same pattern, with a maximum decrease 14 days after the dose. LDL/HDL and $\mathrm{ApoB} / \mathrm{ApoA} 1$ ratios are risk indicators, with greater predictive value than isolated parameters used individually. The ApoB/ApoA 1 and LDL/HDL ratios increased $24 \%$ and $16 \%$, respectively, 14 days after the $500 \mathrm{mg}$ dose, whereas the lowest dose did not affect these ratios.

Unfavorable long-term changes in blood lipid profile may increase the risk of coronary heart disease. It should be noted that lack of testosterone, as in male hypogonadism, has also been associated with unfavorable lipid profile. ${ }^{27}$

Androgen regulation of $\mathrm{p}-\mathrm{Lp}$ (a) was shown by the moderate decrease of $14 \%$ after a single dose of $500 \mathrm{mg}$

Table I Dose-dependent increases in the apolipoprotein B (ApoB)/apolipoprotein AI (ApoAI) and low-density lipoprotein (LDL)/ high-density lipoprotein (HDL) ratios and dose-dependent decreases in HDL, ApoAI, and lipoprotein(a) (Lp[a]) concentrations at 0, 4, and 14 days after parenteral testosterone doses

\begin{tabular}{|c|c|c|c|c|c|c|}
\hline \multirow{2}{*}{$\frac{\text { Dose }}{\text { Day }}$} & \multicolumn{3}{|l|}{$500 \mathrm{mg}$} & \multicolumn{3}{|l|}{$250 \mathrm{mg}$} \\
\hline & 0 & 4 & 14 & 0 & 4 & 14 \\
\hline ApoB/ApoAl & $0.49 \pm 0.03$ & $0.47 \pm 0.03$ & $0.61 \pm 0.03^{\mathrm{a}}$ & $0.52 \pm 0.03$ & $0.53 \pm 0.03$ & $0.55 \pm 0.03$ \\
\hline LDL/HDL & $2.4 I \pm 0.14$ & $2.6 \mathrm{I} \pm 0.18^{\mathrm{b}}$ & $2.86 \pm 0.19^{b}$ & $2.48 \pm 0.19$ & $2.86 \pm 0.19^{b}$ & $2.62 \pm 0.17^{\circ}$ \\
\hline $\mathrm{HDL}, \mathrm{nmol} / \mathrm{L}$ & I. $19 \pm 0.05$ & I. $10 \pm 0.05^{\mathrm{b}}$ & $1.08 \pm 0.04^{b}$ & $1.27 \pm 0.04$ & $1.16 \pm 0.06^{b}$ & I. $12 \pm 0.05^{b}$ \\
\hline ApoAI, g/L & $1.72 \pm 0.07$ & $1.57 \pm 0.06^{\mathrm{a}}$ & $1.4 I \pm 0.05^{\mathrm{a}}$ & $1.67 \pm 0.05$ & $1.58 \pm 0.04$ & $1.56 \pm 0.04$ \\
\hline \multicolumn{7}{|l|}{$L_{p}(\mathrm{a}), \mathrm{mg} / \mathrm{L}$} \\
\hline Median & 96 & 100 & $68^{c}$ & 81 & 105 & 68 \\
\hline Range & $50-589$ & $50-542$ & $50-472$ & $50-603$ & $50-623$ & $50-567$ \\
\hline
\end{tabular}

Notes: "Day 0" refers to values before administration. Analysis of variance repeated-measures adjustment for multiple comparisons, Bonferroni corrected. Results are given as mean \pm standard error of the mean except for those for $L p(a)$, which are given as median and range (Friedman test), as indicated. ${ }^{a} P<0.000 I$; ${ }^{b} P=0.00 I ;{ }^{c} P<0.05$. Data before and after administration of $125 \mathrm{mg}$ of testosterone are not shown. 
of testosterone. This is in agreement with other previous findings. ${ }^{12,16}$ This effect may be of special interest, as the serum concentration of $\mathrm{Lp}$ (a) seems to be genetically determined and cannot be lowered by alterations in food or competitive inhibitors of the 3-hydroxy-3-methylglutaryl-CoA reductase (HMGCR) by statins. ${ }^{28,29}$

The mechanism leading to dyslipidemia in AAS abusers is unclear. Hepatic triglyceride lipase is a strong candidate to mediate the androgen-induced changes in the lipid profile. ${ }^{14} \mathrm{We}$ did not explore the mechanism leading to alterations in blood lipid profile in this study, but our results clearly show a dose-dependent adverse effect on the gonadotropins and s-testosterone, and unfavorable changes in the blood lipid profile.

Vitamin D is mainly known for its role in bone homeostasis and calcium metabolism. But recent studies show that vitamin $\mathrm{D}$ is also involved in processes attracting AAS abusers - that is, its muscle-enhancing properties ${ }^{30}$ and its capacity to inhibit CYP19, the enzyme involved in testosterone aromatization to estrogens and hence decrease in the risk of gynecomastia. ${ }^{31}$ However, the administration of a single dose of $500 \mathrm{mg}$ of testosterone enanthate did not alter the 25-hydroxyvitamin D3 levels. It is possible that long-time abuse of AASs will lead to alteration in vitamin D status. However, this has never been studied in healthy men. Other large studies have found correlation between vitamin $\mathrm{D}$ and circulatory levels of testosterone in men, ${ }^{32,33}$ but the link between vitamin D and testosterone is not known and warrants further investigation.

It is important to address a limitation of this study. Admittedly, the clinical experimental setting is very different from the real-life situation of AAS abusers taking repeated courses for several weeks to several months. The results observed here do not necessarily imply that repeated AAS abuse has the same impact on lipoproteins and hormone status. Individuals using AASs for nonmedical reasons use various dose strategies. Bodybuilders and weightlifters may use as high doses, such as 2,000 $\mathrm{mg}$ per administration time, ${ }^{34}$ whereas some use low doses such as $50 \mathrm{mg}$ (microdoping) to avoid detection in doping tests. ${ }^{35}$ So the range of doses (125-500 mg) used here is highly relevant for steroid abusers.

Our finding that these supra-physiological doses of testosterone have a detrimental effect on the lipid profile further supports previous findings that the supra-physiological use of AASs has a negative effect on the cardiovascular health. ${ }^{36}$

Scientific proof of AAS-induced adverse side effects, together with the epidemiological data showing that the nonmedical use of AASs is a global health problem ${ }^{5}$ implies that public efforts should be centered on primary prevention.

\section{Conclusion}

Our results indicate that testosterone has a more profound and sustained endocrine effect on the hypothalamic-pituitary-gonadal axis than was previously known. We have demonstrated a dose-dependent increase in serum testosterone concentrations concomitant with suppression of s-LH and s-FSH. The minimal dose for alterations in both ApoA1 and HDL, and Lp(a) concentrations was $250 \mathrm{mg}$ and $500 \mathrm{mg}$, respectively in this study. The administration of $500 \mathrm{mg}$ did not alter the concentration of 25-hydroxyvitamin D3. Interestingly, LH and FSH were significantly decreased after the lowest $125 \mathrm{mg}$ dose, which in itself did not yield any measurable change in testosterone serum concentration. These pituitary hormones may therefore be of special interest in doping control programs.

\section{Acknowledgments}

This study was supported by grants from Stockholm County Council and the World Anti-Doping Agency.

\section{Disclosure}

Other than the support outlined in the Acknowledgments section, the authors declare no conflicts of interest in this work.

\section{References}

1. Saudan C, Baume N, Robinson N, Avois L, Mangin P, Saugy M. Testosterone and doping control. Br J Sports Med. 2006;40(1):i21-i24.

2. Lood Y, Eklund A, Garle M, Ahlner J. Anabolic androgenic steroids in police cases in Sweden 1999-2009. Forensic Sci Int. 2012;219(1-3):199-204.

3. Gårevik N, Rane A. Dual use of anabolic-androgenic steroids and narcotics in Sweden. Drug Alcohol Depend. 2010;109(1-3):144-146.

4. Klötz F, Petersson A, Hoffman O, Thiblin I. The significance of anabolic androgenic steroids in a Swedish prison population. Compr Psychiatry. 2010;51(3):312-318.

5. Sagoe D, Molde H, Andreassen CS, Torsheim T, Pallesen S. The global epidemiology of anabolic-androgenic steroid use: a meta-analysis and meta-regression analysis. Ann Epidemiol. 2014;24(5):383-398.

6. Pope HG Jr, Kanayama G, Hudson JI. Risk factors for illicit anabolicandrogenic steroid use in male weightlifters: a cross-sectional cohort study. Biol Psychiatry. 2012;71(3):254-261.

7. Brower KJ. Anabolic steroid abuse and dependence in clinical practice. Phys Sportsmed. 2009;37(4):131-140.

8. Kanayama G, Hudson JI, Pope HG Jr. Illicit anabolic-androgenic steroid use. Horm Behav. 2010;58(1):111-121.

9. Gårevik N, Strahm E, Garle M, et al. Long term perturbation of endocrine parameters and cholesterol metabolism after discontinued abuse of anabolic androgenic steroids. J Steroid Biochem Mol Biol. 2011;127(3-5):295-300.

10. de Souza GL, Hallak J. Anabolic steroids and male infertility: a comprehensive review. BJU Int. 2011;108(11):1860-1865. 
11. Glazer G. Atherogenic effects of anabolic steroids on serum lipid levels. A literature review. Arch Intern Med. 1991;151(10):1925-1933.

12. Hartgens F, Rietjens G, Keizer HA, Kuipers H, Wolffenbuttel BH. Effects of androgenic-anabolic steroids on apolipoproteins and lipoprotein (a). Br J Sports Med. 2004;38(3):253-259.

13. Gårevik N, Skogastierna C, Rane A, Ekström L. Single dose testosterone increases total cholesterol levels and induces the expression of HMG CoA Reductase. Subst Abuse Treat Prev Policy. 2012;7:12.

14. Applebaum-Bowden D, Haffner SM, Hazzard WR. The dyslipoproteinemia of anabolic steroid therapy: increase in hepatic triglyceride lipase precedes the decrease in high density lipoprotein 2 cholesterol. Metabolism. 1987;36(10):949-952.

15. Shirai K, Barnhart RL, Jackson RL. Hydrolysis of human plasma high density lipoprotein 2- phospholipids and triglycerides by hepatic lipase. Biochem Biophys Res Commun. 1981;100(2):591-599.

16. Berglund L, Carlström K, Stege R, et al. Hormonal regulation of serum lipoprotein (a) levels: effects of parenteral administration of estrogen or testosterone in males. J Clin Endocrinol Metab. 1996;81(7):2633-2637.

17. Francomano D, Lenzi A, Aversa A. Effects of five-year treatment with testosterone undecanoate on metabolic and hormonal parameters in ageing men with metabolic syndrome. Int $J$ Endocrinol. 2014:2014:527470.

18. Sottas PE, Robinson N, Rabin O, Saugy M. The athlete biological passport. Clin Chem. 2011;57(7):969-976.

19. Saha S, Mandal MK, Nonami H, Hiraoka K. Direct analysis of anabolic steroids in urine using Leidenfrost phenomenon assisted thermal desorption-dielectric barrier discharge ionization mass spectrometry. Anal Chim Acta. 2014;839:1-7.

20. Van Renterghem P, Polet M, Brooker L, Van Gansbeke W, Van Eenoo P. Development of a GC/C/IRMS method - confirmation of a novel steroid profiling approach in doping control. Steroids. 2012;77(11): 1050-1060.

21. Garle M, Ocka R, Palonek E, Björkhem I. Increased urinary testosterone/ epitestosterone ratios found in Swedish athletes in connection with a national control program. Evaluation of 28 cases. $J$ Chromatogr $B$ Biomed Appl. 1996;687(1):55-59.

22. Alén M, Häkkinen K. Physical health and fitness of an elite bodybuilder during 1 year of self-administration of testosterone and anabolic steroids: a case study. Int J Sports Med. 1985;6(1):24-29.

23. Ekström L, Schulze JJ, Guillemette C, Belanger A, Rane A. Bioavailability of testosterone enanthate dependent on genetic variation in the phosphodiesterase 7B but not on the uridine $5^{\prime}$-diphospho-glu curonosyltransferase (UGT2B17) gene. Pharmacogenet Genomics. 2011;21(6):325-332.
24. Schulze J, Johansson M, Rane A, Ekstrom L. Genetic variation in SLCO2B1 is associated with serum levels of testosterone and its metabolites prior to and two days after testosterone administration. Curr Pharmacogenomics Person Med. 2012;10(3):226-230.

25. Schulze JJ, Lorentzon M, Ohlsson C, et al. Genetic aspects of epitestosterone formation and androgen disposition: influence of polymorphisms in CYP17 and UGT2B enzymes. Pharmacogenet Genomics. 2008;18(6):477-485.

26. Palonek E, Gottlieb C, Garle M, Björkhem I, Carlström K. Serum and urinary markers of exogenous testosterone administration. J Steroid Biochem Mol Biol. 1995;55(1):121-127.

27. Simon D, Charles MA, Nahoul K, et al. Association between plasma total testosterone and cardiovascular risk factors in healthy adult men: The Telecom Study. J Clin Endocrinol Metab. 1997;82(2):682-685.

28. Utermann G. The mysteries of lipoprotein(a). Science. 1989;246(4932):904-910.

29. Shirai K, Barnhart RL, Jackson RL. Hydrolysis of human plasma high density lipoprotein 2- phospholipids and triglycerides by hepatic lipase. Biochem Biophys Res Commun. 1981;100(2):591-599.

30. Girgis CM, Clifton-Bligh RJ, Turner N, Lau SL, Gunton JE. Effects of vitamin $\mathrm{D}$ in skeletal muscle: falls, strength, athletic performance and insulin sensitivity. Clin Endocrinol (Oxf). 2014;80(2):169-181.

31. Villaggio B, Soldano S, Cutolo M. 1,25-dihydroxyvitamin D3 downregulates aromatase expression and inflammatory cytokines in human macrophages. Clin Exp Rheumatol. 2012;30(6):934-938.

32. Wehr E, Pilz S, Boehm BO, März W, Obermayer-Pietsch B. Association of vitamin D status with serum androgen levels in men. Clin Endocrinol. 2010;73(2):243-248.

33. Lee DM, Tajar A, Pye SR, et al; EMAS study group. Association of hypogonadism with vitamin D status: the European Male Ageing Study. Eur J Endocrinol. 2012;166(1):77-85.

34. Evans NA. Gym and tonic: a profile of 100 male steroid users. $\mathrm{Br} J$ Sports Med. 1997;(31):54-58.

35. Raynaud JP, Legros JJ, Rollet J, et al. Efficacy and safety of a new testosterone-in-adhesive matrix patch applied every 2 days for 1 year to hypogonadal men. J Steroid Biochem Mol Biol. 2008;109(1-2): $168-176$.

36. Vanberg P, Atar D. Androgenic anabolic steroid abuse and the cardiovascular system. Handb Exp Pharmacol. 2010;(195):411-457.
Substance Abuse and Rehabilitation

\section{Publish your work in this journal}

Substance Abuse and Rehabilitation is an international, peer-reviewed, open access journal publishing original research, case reports, editorials, reviews and commentaries on all areas of addiction and substance abuse and options for treatment and rehabilitation. The manuscript management system is completely online and includes a very quick and fair

\section{Dovepress}

peer-review system. Visit http://www.dovepress.com/testimonials.php to read real quotes from published authors. 